\title{
Importance of studying primitive neuroectodermal tumors and extraosseous Ewing's sarcoma of the vagina and vulva (Review)
}

\author{
ADELINE TINTILA $^{1}$, BOGDAN DOROFTEI ${ }^{2-4}$, DELIA GRAB ${ }^{2,3}$, GABRIELA SIMIONESCU $^{2-4}$, \\ EMIL ANTON $^{2,3}$, RADU MAFTEI ${ }^{2}$, CIPRIAN ILEA $^{2,3}$ and CARMEN ANTON ${ }^{5,6}$
}

\begin{abstract}
${ }^{1}$ Clinical Department, Spitalul Judetean Suceava, Suceava 720224; ${ }^{2}$ Department of Obstetrics and Gynecology, University of Medicine and Pharmacy 'Grigore T. Popa', Iasi 700115; ${ }^{3}$ Clinical Department, Clinical Hospital of Obstetrics and Gynecology 'Cuza Voda', Iasi 700038; ${ }^{4}$ Clinical Department, Origyn Fertility Center, Iasi 700032;

${ }^{5}$ Clinical Department, Sf. Spiridon Clinical Hospital, Iasi 700111; ${ }^{6}$ Department of Gastroenterology, University of Medicine and Pharmacy 'Grigore T. Popa', Iasi 700115, Romania
\end{abstract}

Received July 27, 2020; Accepted November 11, 2020

DOI: $10.3892 / \mathrm{ol} .2021 .12432$

\begin{abstract}
Primitive neuroectodermal tumor (PNT) and Ewing's sarcoma are rare, round-cell tumors, characterized by the presence of the $\mathrm{t}(11 ; 22)(\mathrm{q} 24 ; \mathrm{q} 12)$ chromosomal translocation. A review of the literature revealed only 38 previously reported cases of vulvar PNT and Ewing's sarcoma and 15 vaginal PNT and Ewing's sarcoma. Although rare, these types of tumors should be taken into consideration when making a differential diagnosis for vulvar or vaginal tumors. The currently available data is limited, and therefore, case reports are essential for improving knowledge and management of these types of extremely rare tumors. However, further molecular and histopathological studies are essential for an improved understanding of these conditions and for an early, correct diagnosis. Although the gathered and presented data from the present review are limited, the literature demonstrates that the outcome of these types of cancer are more favorable compared with outcomes observed for carcinomas in more typical locations.
\end{abstract}

\section{Contents}

1. Introduction

Correspondence to: Dr Emil Anton, Department of Obstetrics and Gynecology, University of Medicine and Pharmacy 'Grigore T. Popa', 11 Universitatii Street, Iasi 700115, Romania

E-mail: emil.anton@yahoo.com

Abbreviations: PNT, primitive neuroectodermal tumors; MRI, magnetic resonance imaging; CT, computed tomography; CK20, cytokeratin 20; CK7, cytokeratin 7; EWSR1, Ewing's sarcoma RNA-binding protein 1

Key words: rare tumors, primitive neuroectodermal tumors, extraosseous Ewing's sarcoma
2. Methodology

3. Clinical and paraclinical evaluation

4. Immunohistochemical and genetic aspects in differential diagnosis

5. Location

6. Prognostic factors

7. Treatment

8. Conclusions

\section{Introduction}

Ewing's sarcoma and primitive neuroectodermal tumor (PNT) are considered sarcomas with round cells and fluctuating levels of neuroectodermal differentiation. These types of cancer are distinguished by genetic translocation, wherein the Ewing's sarcoma breakpoint region 1 (EWSR1) gene binds to the DNA-fusing domain of an erythroblast transformation-specific (ETS) transcription factor gene. In Ewing's sarcoma, although there are five different ETS factors that fuse with EWSR1, FLI1 is the most common factor reported in up to $95 \%$ of cases (1).

Friend leukemia virus-induced erythroleukemia-1 (FLI-1) is an ETS transcription factor that acts as a key regulator of normal development and malignant transformation. There is evidence that FLI-1 serves an important role in the maintenance, differentiation, hematopoiesis, vasculogenesis, and angiogenesis of stem cells (2). Consequently, any perturbation of ETS factor activity will induce tumor initiation, progression and metastasis. Studies have also demonstrated that the major cause of aberrant ETS expression in leukemia is chromosomal translocation (2,3). In addition, ETS factors have been demonstrated to have implication in the development of various solid tumors $(2,3)$.

Therefore, Ewing's sarcoma and PNT have chromosomal aberration, which is expressed by translocation, wherein one gene from the Ewing's sarcoma gene on $22 \mathrm{q} 12$ is fused with another gene, a member of the ETS group of transcription factors. More precisely, the most recurrent gene involved in this process is $\mathrm{t}(11 ; 22)(\mathrm{q} 24 ; \mathrm{q} 12)$, which is a result of the fusion of the FLI1 gene with the Ewing's sarcoma gene (4). 
The entire molecular mechanism occurs in $85 \%$ of the Ewing's sarcoma cases or PNTs, with the other $15 \%$ of cases involving $\mathrm{t}(21 ; 22)(\mathrm{q} 22 ; \mathrm{q} 12)$ translocation. These translocations result in the formation of certain fusion genes that encode various novel chimeric transcription factors (5). These factors are considered to be vital to the tumor biology because they alter the critical control points of cell differentiation and proliferation through aberrant regulation of gene expression (6).

Therefore, given that Ewing's sarcoma and PNT share numerous genetic features, they are considered members of the same family of tumors, i.e., the Ewing's family of tumors. However, the two entities differ in that PNTs refer to neoplasms that present with neuroectodermal differentiation, as determined using various methods, including microscopy, ultrastructural studies or immunohistochemistry, which Ewing's sarcoma refers to tumors that lack evidence of this type of differentiation (7).

The Ewing's family of tumors is a group of tumors of mesenchymal origin, which account for $4 \%$ of all neoplasms and occur more commonly in the first two decades of life (8). There are several main types of tumor belonging to the Ewing's family of tumors. However, the most well-known tumor from this family is Ewing's sarcoma of the bone, which was first described in 1921 by the American pathologist James Ewing, who found differences between this tumor and osteosarcoma, the most common malignant bone tumor (9).

Another tumor from the Ewing's family of tumors is the extraosseous Ewing's sarcoma. The first case of extraosseous Ewing's sarcoma was reported in 1975 when Angervall and Enzinger validated the diagnosis of this tumor after analyzing 39 cases (10).

Furthermore, PNT is a type of tumor that belongs to the Ewing's family of tumors. PNT was first mentioned in 1918 by Arthur Stout, who described a tumor of the ulnar nerve that had small, round cells (11).

Of all these types, PNT and extraosseous Ewing's sarcoma of the female genital tract are more aggressive. However, regarding the location of the PNT and extraosseous Ewing's sarcomas of the female genital tract, the most common sarcoma is one that develops in the ovaries. PNT and Ewing's sarcoma of the cervix, vagina and vulva are extremely rare $(12,13)$. Data regarding these tumors are very limited, and there are no standard guidelines for the pathology, diagnosis or treatment of these types of cancer (14-16).

Therefore, the main objective of the present review was to investigate the limited available data and to emphasize the clinical and paraclinical aspects and the recommended treatment for PNT and extraosseous Ewing's sarcoma located in the vulva and vagina.

\section{Methodology}

The inquired databases (from 1960 until July 2020) were Medline, Embase, Cancerlit, DARE and Cochrane Database of Systematic Reviews. The keywords used in the search strategy were 'extraosseous Ewing's sarcoma', 'primitive neuroectodermal tumor', 'PNT', 'extraosseous Ewing's sarcoma case report', 'primitive neuroectodermal tumor case report' and 'PNT case report'.
A total of 38 cases of PNT or Ewing's sarcoma with vulvar localization were identified. The majority of the identified patients were young $(<30$ years old), and the youngest and the oldest of the patients were 3 years and 87 years, respectively (Table I) $(5,9,13,16-43)$. Regarding vaginal PNT and extraosseous Ewing's sarcoma, 15 cases (14 and 1, respectively) have been recorded in the literature, and they were reported to occur in patients aged 12-54 years, and the first case was described in 1970 (Table II) $(12,21,25,44-54)$.

\section{Clinical and paraclinical evaluation}

The clinical findings in vulvar PNT or extraosseous Ewing's sarcoma vary from the presence of a rapidly growing tumor to a cystic or peduncled appearance on the labia majora, labia minora or clitoris, or to the presence of ulceration or inguinal lymphadenopathy (16-43,55).

Therefore, complete clinical examination is essential to assess local extension, and more attention must be paid to the inguinal lymph nodes. In locally advanced cases, magnetic resonance imaging or computed tomography should be performed (56). In the case of suspected lymphadenopathy, fine needle aspiration may be performed under ultrasound guidance (56). Distant metastases present at the time of diagnosis are rare and indicate a reserved prognosis, as most often, these lesions are located in the lungs $(19,24,25,28,42,56)$.

Regarding the differential diagnosis of vulvar PNT or extraosseous Ewing's sarcomas, the diagnoses of genital herpes, inguinal granuloma caused by Klebsiella granulomatis, chancroid due to Haemophilus ducreyi, rhabdomyosarcoma, malignant fibrous histocytoma, leiomyosarcoma, epithelioid sarcoma, neuroblastoma, Paget's disease of the vulva, lymphoma, small cell carcinoma, malignant melanoma ( $10 \%$ of vulvar tumors), Merkel cell carcinoma, squamous cell carcinoma of the vulva, Bartholin's gland cyst, Bartholin's gland carcinoma, basal cell carcinoma of the vulva, vulvar wart carcinoma and metastases from other organs should first be excluded $(26,33,56)$.

In addition, vaginal PNT or extraosseous Ewing's sarcoma may cause various symptoms, including vaginal bleeding or a painless intravaginal tumor (36). Therefore, the differential diagnosis of vaginal PNT and extraosseous Ewing's sarcoma should be made with benign vaginal lesions, extrauterine leiomyomas or lipomas (33).

Furthermore, PNT and extraosseous Ewing's sarcoma are histologically characterized by the presence of small blue cells with a rosette-like pattern, but diagnosing is difficult due to, not only the similar findings on the usual staining, but also their similarity with other types of small cell tumors, including rhabdomyosarcoma, osteosarcoma, non-Hodgkin's lymphoma, Merkel cell tumors, malignant melanoma and other primary small cell tumors and their metastases (19).

Therefore, once the diagnosis of PNT or extraosseous Ewing's sarcomas is made, the next step is to differentiate between the two. The differences between PNT and extraosseous Ewing's sarcoma are that, unlike PNT, Ewing's sarcomas have no neuroectodermal differentiation (12). Therefore, in electron microscopy, the presence of neurosecretory granules may differentiate PNT from Ewing's sarcoma. 
Table I. Available case reports of vulvar extraosseous Ewing's sarcoma or primitive neuroectodermal tumors.

\begin{tabular}{|c|c|c|c|c|c|}
\hline $\begin{array}{l}\text { Year of } \\
\text { publication }\end{array}$ & Author(s) & Patient's age & Location & Symptoms & Reference \\
\hline 2014 & Narayanan et al & 17 & Clitoris & Swelling & (7) \\
\hline 2017 & Yang et al & 20 & Left labium majus & Growing painful mass & $(9)$ \\
\hline 2010 & Dadhwal et al & 20 & Right labium majus & Growing tumor & (13) \\
\hline \multirow[t]{2}{*}{2014} & Xiao et al & 20 & Left labium majus & Painful tumor & (16) \\
\hline & & 36 & Right labium majus & Painful tumor & \\
\hline 1994 & Scherr et al & 10 & Left labium majus & Painless tumor & (18) \\
\hline 1995 & Paredes et al & 29 & Left labium majus & Painful tumor & (19) \\
\hline \multirow[t]{10}{*}{1995} & Nirenberg et al & 35 & Right labium majus & Painless tumor & $(20)$ \\
\hline & & 31 & Right labium majus & Painless tumor & \\
\hline & & 30 & Right vulva & Painless tumor & \\
\hline & & 54 & Right vulva & Painless tumor & \\
\hline & & 51 & Clitoris & Painless tumor & \\
\hline & & 41 & Left labium majus & Painless tumor & \\
\hline & & 29 & Right labium majus & Growing painless tumor & \\
\hline & & 44 & Right labium minus & Growing Painless tumor & \\
\hline & & 87 & Mons pubis & Painless tumor & \\
\hline & & 20 & Right labium majus & Growing Painless tumor & \\
\hline 2000 & Vang et al & 28 & Dermis of the vulva & Painless tumor & $(21)$ \\
\hline 2001 & Takeshima et al & 45 & Right labium majus & Painless tumor & $(22)$ \\
\hline 2001 & Lazure et al & 29 & Dermis of the vulva & Painless tumor & (23) \\
\hline 2005 & $\begin{array}{l}\text { Moodley } \\
\text { and Jordaan }\end{array}$ & 26 & Lower right labium majus & Painless tumor & (24) \\
\hline \multirow[t]{3}{*}{2007} & McCluggage et al & 40 & Right labium minus & Painless tumor & $(25)$ \\
\hline & & 20 & Right labium & Painless tumor & \\
\hline & & 19 & Dermis of the vulva & Painless tumor & \\
\hline 2008 & Fong et al & 17 & Left vulva & Painless tumor & (26) \\
\hline \multirow[t]{2}{*}{2009} & Cetiner et al & 23 & Left labium majus & Painful tumor & (27) \\
\hline & & 29 & Left vulva & Painless tumor & \\
\hline 2012 & Kelling et al & 18 & Right labium majus & Growing painless tumor & (28) \\
\hline 2010 & Boldorini et al & 52 & Lower right labium majus & Painless tumor & (29) \\
\hline 2018 & Pei et al & 33 & Right vulva & Painless tumor & (30) \\
\hline 2017 & Chiang et al & 65 & Vulva & Painless tumor & $(31)$ \\
\hline 2019 & $\mathrm{Xu}$ et al & 3 & Vulva & Painless tumor & $(32)$ \\
\hline 2015 & Tunitsky-Bitton et al & 15 & Left labium minus & Painful tumor & $(33)$ \\
\hline 2015 & Rekhi et al & 10 & Left vulva & Painless swelling & $(35)$ \\
\hline 2014 & Matsuda et al & 60 & Right vulva & Painless tumor & $(36)$ \\
\hline 2013 & Che et al & 38 & Left labium majus & Painless tumor & (37) \\
\hline 2019 & Cantos et al & 52 & Clitoris & Growing painless tumor & $(40)$ \\
\hline 2017 & Kakoti et al & 16 & Left vulva & Growing tumor with severe pain & (41) \\
\hline
\end{tabular}

\section{Immunohistochemical and genetic aspects in differen- tial diagnosis}

From an immunohistochemical perspective, the CD99 marker may be found in 97\% of cases of PNT and extraosseous Ewing's sarcoma (57). Another immunohistochemical characteristic of PNT and extraosseous Ewing's sarcoma is the lack of expression of the CD20 marker, which is specific for B-cell lymphoma, and CD15, which occurs in several types of leukemia and Hodgkin's lymphoma (16).
In terms of the differences from other types of cancer, cytokeratin (AE1/AE3) expression is positive in Merkel cell carcinoma and small cell lung cancer, is rarely positive in Ewing's sarcoma and malignant melanoma, and is negative in lymphoma (58). Cytokeratin 20 (CK20) expression is positive in Merkel cell carcinoma, but negative in small cell lung cancer, lymphoma, malignant melanoma and Ewing's sarcoma (58). Cytokeratin 7 (CK7) expression is positive in small cell lung cancer, but negative in Merkel cell carcinoma, lymphoma, malignant melanoma and Ewing's sarcoma (58). 
Table II. Available case reports of vaginal extraosseous Ewing's sarcoma or primitive neuroectodermal tumors.

\begin{tabular}{|c|c|c|c|c|c|}
\hline $\begin{array}{l}\text { Year of } \\
\text { publication }\end{array}$ & Author(s) & Patient's age & Location & Symptoms & Reference \\
\hline 2000 & Vang et al & 35 & Vagina & Painless tumor & $(21)$ \\
\hline 2000 & Farley et al & 35 & Vagina & Painless tumor & (44) \\
\hline 2002 & Petković et al & 45 & $\begin{array}{l}\text { Recto-vaginal } \\
\text { septum }\end{array}$ & Painful tumor & $(50)$ \\
\hline 2003 & Gaona-Luviano et al & 34 & Vagina & Painless tumor & $(45)$ \\
\hline 2004 & Liao et al & 30 & Vagina & Painless tumor & $(46)$ \\
\hline 2007 & McCluggage et al & 30 & Vagina & Painless tumor & $(25)$ \\
\hline 2009 & Al-Tamimi et al & 47 & Vagina & Painless tumor & $(47)$ \\
\hline 2009 & Yip et al & 28 & Vagina & Painless tumor, discharge & $(48)$ \\
\hline 2010 & Rekhi et al & 17 & Vagina & Painless tumor, discharge & (12) \\
\hline 2013 & Machado et al & 32 & Vagina & Painless tumor, discharge & $(51)$ \\
\hline 2012 & Bancalari et al & 39 & Vagina & Bleeding tumor & $(49)$ \\
\hline 2012 & Pang et al & 54 & Vagina & Bleeding two tumors & $(52)$ \\
\hline 2016 & Modi et al & 34 & Vagina & Painless tumor, bleeding & $(53)$ \\
\hline \multirow[t]{2}{*}{2017} & Cross et al & 12 & Vagina & Painless tumor, discharge, bleeding & $(54)$ \\
\hline & & 15 & Vagina & $\begin{array}{l}\text { Abdominal discomfort, bleeding, } \\
\text { discharge, painless tumor }\end{array}$ & $(54)$ \\
\hline
\end{tabular}

Table III. Immunohistochemical aspects in differential diagnoses of Ewing's sarcoma.

\begin{tabular}{ll}
\hline Positive in Ewing's sarcoma & Negative in Ewing's sarcoma \\
\hline CD99 markers & CD20 markers \\
S-100 protein & CD15 markers \\
expression & \\
CD56 expression & Cytokeratin expression \\
& (AE1/AE3) \\
& Cytokeratin 20 \\
& Cytokeratin 7 \\
& Thyroid transcription factor \\
\end{tabular}

Furthermore, the expression of thyroid transcription factor or the mammalian achaete-scute homolog 1 gene is positive in non-small cell lung cancer, but negative in small cell lung cancer, malignant melanoma, lymphoma and Ewing's sarcoma (59). In addition, S-100 protein expression is positive in Merkel cell carcinoma, lymphoma, lung cancer and Ewing's sarcoma (60). However, S-100 protein expression is negative in malignant melanoma (60).

Finally, the expression of chromogranin A and B, proteins located in the secretory vesicles, and CD56 is positive in malignant melanoma, neuroendocrine tumors, small cell lung cancer, and Merkel cell carcinoma, but negative in lymphoma (Table III) (61). However, from a genetic perspective, PNT and extraosseous Ewing's sarcomas exhibit the chromosomal abnormality $\mathrm{t}(11 ; 22)(\mathrm{q} 24 ; \mathrm{q} 12)$, which involves the binding of the EWSR1 gene with the FLI1 gene, which encodes the EWS/FLI fusion protein. This translocation is essential to confirm the diagnosis of rare tumors, including PNT and extraosseous Ewing's sarcoma of the vulva or vagina $(13,18,33,49)$.

\section{Location}

Although the literature has extremely limited data regarding the incidence, information on the location of extraosseous Ewing's sarcoma and PNT demonstrates that $230 \%$ of the tumors are located in the paravertebral region (62), $25 \%$ in the lower extremities (62), 20\% in the chest wall (63), $10 \%$ in the pelvic region (64-66), 10\% in the retroperitoneum (63), $5 \%$ in the head and neck (67), and $<1 \%$ in the upper extremities (10).

\section{Prognostic factors}

Extraosseous Ewing's sarcomas have a generally reserved prognosis, but patients with vulvar localization appear to have a better prognosis, possibly due to localization and detection at an early stage, and the ability to perform surgery with negative margins (37).

PNTs appear to be more aggressive than Ewing's sarcomas (18). Furthermore, Serlo et al (68) demonstrated that younger patients have a better prognosis, and the use of adjuvant chemotherapy also improves prognosis. As in Ewing's sarcoma of the bone, the most unfavorable prognosis is determined by the presence of secondary disseminations, locally advanced disease, surgical resection with positive margin and resistance to chemotherapy (69).

\section{Treatment}

Given the rarity of cases, there are no guidelines for the treatment of these types of tumors. The treatments are often multimodal, depending on the location, extent and characteristics of the tumors. The recommended treatments include surgery, radiotherapy and systemic chemotherapy. 
Chemotherapy may be neoadjuvant, adjuvant or palliative. However, when feasible, surgery is always recommended first. Adjuvant chemotherapy has demonstrated significant survival benefit. The main chemotherapeutic agents used in the treatment of PNT and extraosseous Ewing's sarcomas are those that are also used for Ewing's sarcoma of the bone. The chemotherapeutic agents that have been used successfully on PNT and extraosseous Ewing's sarcoma are vincristine, doxorubicin, cyclophosphamide, actinomycin-D, ifosfamide and etoposide. Furthermore, the use of the oral tyrosine kinase inhibitor, pazopanib, has shown beneficial effects $(33,70)$.

In addition, there is an increased interest in developing a treatment approach based on redox-modulating chemotherapeutics (71). This in-development type of treatment is based on the idea that oxidative stress and redox regulation may serve vital causative roles in the initiation and progression of numerous cancer types. The therapy is based on direct or indirect pro-oxidant approaches, which are referred to as redox therapeutics (72). Two distinct directions have been proposed for the development of the therapy: the first one is oxidant-generating therapy, which refers to the possibility of enhancing the intracellular concentration of reactive oxygen species (ROS), while the second one is antioxidant-inhibitor therapy, which involves inhibiting the antioxidant defense systems of cancer (73). The assumption underlying these two treatments is that enhancing intracellular levels of ROS above the capacity of endogenous antioxidant defenses will destroy the tumor cells.

\section{Conclusions}

Although PNT and extraosseous Ewing's sarcoma are very rare tumors, they should be taken into consideration when making a differential diagnosis for tumors of the lower gynecological tract. In addition, Ewing's sarcomas and PNTs are more commonly described as a painless mass in the older age group than in the younger age group. The diagnosis should be made using histological and immunohistochemical analyses and should be confirmed by molecular techniques, given its rarity. However, further molecular and histopathological studies are essential for a better understanding of these conditions and for an early, accurate diagnosis. Although the gathered and presented information from the present review is limited, the literature demonstrates that the outcomes of these types of cancer appear to be more favorable than those observed for carcinomas in more typical locations.

\section{Acknowledgements}

Not applicable.

\section{Funding}

No funding was received.

\section{Availability of data and materials}

All data generated or analyzed during this study are included in this published article.

\section{Authors' contributions}

AT, BD, EA and CA made substanțial contributions to the conception of the study. DG, GS, RM and CI acquired data. AT, BD, EA and CA contributed to analysis and interpretation of data. DG, GS RM and CI wrote the paper. All authors have read and approved the manuscript.

\section{Ethics approval and consent to participate}

Not applicable.

\section{Patient consent for publication}

Not applicable.

\section{Competing interests}

The authors declare that they have no competing interests.

\section{References}

1. Embree LJ, Azuma M and Hickstein DD: Ewing sarcoma fusion protein EWSR1/FLI1 interacts with EWSR1 leading to mitotic defects in zebrafish embryos and human cell lines. Cancer Res 69: 4363-4371, 2009.

2. Sizemore GM, Pitarresi JR, Balakrishnan S and Ostrowski MC: The ETS family of oncogenic transcription factors in solid tumours. Nat Rev Cancer 17: 337-351, 2017.

3. Li Y, Luo H, Liu T, Zacksenhaus E and Ben-David Y: The ets transcription factor Fli-1 in development, cancer and disease. Oncogene 34: 2022-2031, 2015.

4. Delattre O, Zucman J, Melot T, Garau XS, Zucker JM, Lenoir GM, Ambros PF, Sheer D, Turc-Carel C, Triche TJ, et al: The Ewing family of tumors - a subgroup of small-round-cell tumors defined by specific chimeric transcripts. N Engl J Med 331: 294-299, 1994.

5. Delattre O, Zucman J, Plougastel B, Desmaze C, Melot T, Peter M, Kovar H, Joubert I, de Jong P, Rouleau G, et al: Gene fusion with an ETS DNA-binding domain caused by chromosome translocation in human tumours. Nature 359: 162-165, 1992.

6. Wang X, Gao Y, Xu Y, Liu Y and Qu P: Primary primitive neuroectodermal tumor of the cervix: A report of two cases and review of the literature. Mol Clin Oncol 6: 697-700, 2017.

7. Narayanan G, Rajan V, Puthusseri J, Kattoor J and Soman LV: Primitive Neuroectodermal Tumor of the Vulva in an Adolescent Girl. World J Oncol 5: 220-222, 2014.

8. Song HC, Sun N, Zhang WP and Huang CR: Primary Ewing's sarcoma/primitive neuroectodermal tumor of the urogenital tract in children. Chin Med J (Engl) 125: 932-936, 2012.

9. Yang J, Guo Q, Yang Y, Zhang J, Lang J and Shi H: Primary vulvar Ewing sarcoma/primitive neuroectodermal tumor: A report of one case and review of the literature. J Pediatr Adolesc Gynecol 25: e93-e97, 2012.

10. Angervall L and Enzinger FM: Extraskeletal neoplasm resembling Ewing's sarcoma. Cancer 36: 240-251, 1975.

11. Pomara G, Cappello F, Cuttano MG, Rappa F, Morelli G, Mancini P and Selli C: Primitive Neuroectodermal Tumor (PNET) of the kidney: A case report. BMC Cancer 4: 3, 2004.

12. Rekhi B, Qureshi S, Basak R, Desai SB, Medhi S, Kurkure P, Menon S, Maheshwari A and Jambhekar NA: Primary vaginal Ewing's sarcoma or primitive neuroectodermal tumor in a 17-year-old woman: A case report. J Med Case Reports 4: 88, 2010.

13. Dadhwal V, Bahadur A, Gupta R, Bansal S and Mittal S: Peripheral neuroectodermal tumor of the vulva: A case report. J Low Genit Tract Dis 14: 59-62, 2010.

14. Mittal S, Sumana G, Gupta M and Gupta B: Primitive neuroectodermal tumor of the uterus: A case report. Int J Gynecol Cancer 17: 524-527, 2007. 
15. Snijders-Keilholz A, Ewing P, Seynaeve C and Burger CW: Primitive neuroectodermal tumor of the cervix uteri: A case report - changing concepts in therapy. Gynecol Oncol 98: $516-519,2005$

16. Xiao C, Zhao J, Guo P, Wang D, Zhao D, Ren T, Yang J, Shen K, Lang J, Xiang Y, et al: Clinical analysis of primary primitive neuroectodermal tumors in the female genital tract. Int J Gynecol Cancer 24: 404-409, 2014.

17. Habib K, Finet JF, Plantier F, Spatz A, Sfoggia D and Fitoussi F: Lésion rare de la vulve. Arch Anat Cytol Pathol 40: 158-159, 1992 (In French).

18. Scherr GR, d'Ablaing G III and Ouzounian JG: Peripheral primitive neuroectodermal tumor of the vulva. Gynecol Oncol 54: 254-258, 1994

19. Paredes E, Duarte A, Couceiro A, Fernandes D, Alves A and Bastos S: A peripheral neuroectodermal tumor of the vulva. Acta Med Port 8: 161-163, 1995 (In Portuguese).

20. Nirenberg A, Ostör AG, Slavin J, Riley CB and Rome RM: Primary vulvar sarcomas. Int J Gynecol Pathol 14: 55-62, 1995.

21. Vang R, Taubenberger JK, Mannion CM, Bijwaard K, Malpica A Ordonez NG, Tavassoli FA and Silver SA: Primary vulvar and vaginal extraosseous Ewing's sarcoma/peripheral neuroectodermal tumor: Diagnostic confirmation with CD99 immunostaining and reverse transcriptase-polymerase chain reaction. Int J Gynecol Pathol 19: 103-109, 2000.

22. Takeshima N, Tabata T, Nishida H, Furuta N, Tsuzuku M Hirai Y and Hasumi K: Peripheral primitive neuroectodermal tumor of the vulva: Report of a case with imprint cytology. Acta Cytol 45: 1049-1052, 2001

23. Lazure T, Alsamad IA, Meuric S, Orbach D and Fabre M: Sarcomes d'Ewing/tumeurs neuroectodermiques primitives périphériques de l'utérus et de la vulve chez l'enfant: Deux localisations exceptionnelles. Ann Pathol 21: 263-266, 2001 (In French)

24. Moodley M and Jordaan A: Ewing's sarcoma of the vulva - a case report. Int J Gynecol Cancer 15: 1177-1178, 2005.

25. McCluggage WG, Sumathi VP, Nucci MR, Hirsch M, Dal Cin P, Wells M, Flanagan AM and Fisher C: Ewing family of tumours involving the vulva and vagina: Report of a series of four cases. J Clin Pathol 60: 674-680, 2007.

26. Fong YE, López-Terrada D and Zhai QJ: Primary Ewing sarcoma/peripheral primitive neuroectodermal tumor of the vulva. Hum Pathol 39: 1535-1539, 2008.

27. Cetiner H, Kir G, Gelmann EP and Ozdemirli M: Primary vulvar Ewing sarcoma/primitive neuroectodermal tumor: A report of 2 cases and review of the literature. Int J Gynecol Cancer 19 1131-1136, 2009.

28. Kelling K, Noack F, Altgassen C, Kujath P, Bohlmann MK and Hoellen F: Primary metastasized extraskeletal Ewing sarcoma of the vulva: Report of a case and review of the literature. Arch Gynecol Obstet 285: 785-789, 2012.

29. Boldorini R, RiboniF,CristinaS, Allegrini S, Valentini S,Muscarà M and Ruspa G: Primary vulvar Ewing's sarcoma/primitive neuroectodermal tumor in a post-menopausal woman: A case report. Pathol Res Pract 206: 476-479, 2010.

30. Pei Y,Zhang BZ, Xu GC and Xiao JJ: A case of vulva with pelvic metastasis of Ewing sarcoma and review of literature. Shanx Yike Daxue Xuebao 49: 325-327, 2018 (In Chinese).

31. Chiang S, Snuderl M, Kojiro-Sanada S, Quer Pi-Sunyer A, Daya D, Hayashi T, Bosincu L, Ogawa F, Rosenberg AE, Horn LC, et al: Primitive neuroectodermal tumors of the female genital tract: A morphologic, immunohistochemical, and molecular study of 19 cases. Am J Surg Pathol 41: 761-772, 2017.

32. Xu QQ, Xing WW, Chen G, Dang YW, Luo YG, Chen P, Liang SW and Chen JB: Primitive neuroectodermal tumors of the abdomina wall and vulva in children: Report of two cases and review of the literature. World J Clin Cases 7: 3671-3682, 2019.

33. Tunitsky-Bitton E, Uy-Kroh MJ, Michener C and Tarr ME: Primary Ewing sarcoma presenting as a vulvar mass in an adolescent: Case report and review of literature. J Pediat Adolesc Gynecol 28: e179-e183, 2015.

34. Huang YR, Kang JL and Li QT: Case of cranial metastasis of primitive neuroectodermal tumor of vulva. Guangdong Yixue 36: 3096, 2015.

35. Rekhi B, Chinnaswamy G, Vora T, Shah S and Rangarajan V: Primary Ewing sarcoma of vulva, confirmed with molecular cytogenetic analysis: A rare case report with diagnostic and treatment implications. Indian J Pathol Microbiol 58: 341-344, 2015.

36. Matsuda M, Ichimura T, Kasai M, Murakami M, Hoshi M, Kawamura N and Sumi T: Primitive neuroectodermal tumor originating in the vulva: A case report. Oncol Lett 8: 187-189, 2014.
37. Che SM, Cao PL, Chen HW, Liu Z and Meng D: Primary Ewing's sarcoma of vulva: A case report and a review of the literature. J Obstet Gynaecol Res 39: 746-749, 2013.

38. Anastasiades EN, El Abiad SA and Chouairy CJ: Ewing sarcoma/ primitive neuroectodermal tumor (PNET) of the vulva. Case report and review of the literature. J Med Liban 60: 113-116, 2012.

39. Dong YJ, Wang WZ and Zhong DR: Clinicopathological features of primary peripheral primitive neuroectodermal tumors of vulva: A report of 3 case. Linchuang Yu Shiyan Binglixue Zazhi 28: 98-100, 2012 (In Chinese).

40. Cantos M, Agrawal A, Chibbar R and Theoret C: An unusual finding of vulvar Ewing sarcoma - a case report and review of literature. Eur J Gynaecol Oncol 40: 849-855, 2019.

41. Kakoti LM, Sharma JD, Kataki AC and Barmon D: Primary Ewing sarcoma of vulva: A case report and a review of literature. Indian J Gynecol Oncol 15: 15, 2017.

42. Halil S, Kucuk M, Arvas M, Aydin O and Calay ZZ: Peripheral primitive neuroectodermal tumor (PNET) of the vulva: A case report. Eur J Gynaecol Oncol 32: 117-118, 2011.

43. Tang X, Wang P, He Y, Yang F, Li L, Wang H, Wang QL, Yao XY and Yang KX: Primitive neuroectodermal tumor in female genital tract: A clinicopathologic study. Zhonghua Bing Li Xue Za Zhi 41: 729-732, 2012 (In Chinese).

44. Farley J, O'Boyle JD, Heaton J and Remmenga S: Extraosseous Ewing sarcoma of the vagina. Obstet Gynecol 96: 832-834, 2000

45. Gaona-Luviano P, Unda-Franco E, González-Jara L, Romero P and Medina-Franco H: Primitive neuroectodermal tumor of the vagina. Gynecol Oncol 91: 456-458, 2003.

46. Liao X, Xin X and Lü X: Primary Ewing's sarcoma-primitive neuroectodermal tumor of the vagina. Gynecol Oncol 92: 684-688, 2004.

47. Al-Tamimi H, Al-Hadi AA, Al-Khater AH, Al-Bozom I and Al-Sayed N: Extraskeletal neuroectodermal tumour of the vagina: A single case report and review. Arch Gynecol Obstet 280: 465-468, 2009

48. Yip CM, Hsu SS, Chang NJ, Wang JS, Liao WC, Chen JY, Liu SH and Chen $\mathrm{CH}$ : Primary vaginal extraosseous Ewing sarcoma/primitive neuroectodermal tumor with cranial metastasis. J Chin Med Assoc 72: 332-335, 2009.

49. Bancalari E, de Álava E and Tardío JC: Primary vaginal Ewing sarcoma: Case report and review of the literature. Int J Surg Pathol 20: 305-310,2012.

50. Petković M, Zamolo G, Muhvić D, Coklo M, Stifter S and Antulov R: The first report of extraosseous Ewing's sarcoma in the rectovaginal septum. Tumori 88: 345-346, 2002

51. Machado L, Al-Hamdani A, Sankhla DK and Al-Moundhri MS: Extraosseous Ewing sarcoma of the vagina: A rare entity. Ann Saudi Med 33: 182-186, 2013.

52. Pang $X$, Chen P, Wen F and Zhang Y: Primary Ewing's sarcoma/primitive neuroectodermal tumor of the vagina in a 54-year-old woman: A case report. Arch Gynecol Obstet 285: 1031-1033, 2012

53. Modi G, Madabhavi I, Patel A, Anand A, Panchal H, Parikh S, Baldaniya $\mathrm{K}$ and Revannasiddaiah S: Primary vaginal Ewing's sarcoma: A rare case report. J Obstet Gynaecol India 66 (Suppl 2): 690-693, 2016.

54. Cross NM, Stanescu AL, Rudzinski ER, Hawkins DS and Parisi MT: Vaginal Ewing sarcoma: An uncommon clinical entity in pediatric patients. J Clin Imaging Sci 7: 17, 2017.

55. Heare T, Hensley MA and Dell'Orfano S: Bone tumors: Osteosarcoma and Ewing's sarcoma. Curr Opin Pediatr 21: 365-372, 2009.

56. Stehman FB and Look KY: Carcinoma of the vulva. Obstet Gynecol 107: 719-733, 2006.

57. Rocchi A, Manara MC Sciandra M, Zambelli D, Nardi F, Nicoletti G, Garofalo C, Meschini S, Astolfi A, Colombo MP, et al: CD99 inhibits neural differentiation of human Ewing sarcoma cells and thereby contributes to oncogenesis. J Clin Invest 120: 668-680, 2010

58. Gu M, Antonescu CR, Guiter G, Huvos AG, Ladanyi M and Zakowski MF: Cytokeratin immunoreactivity in Ewing's sarcoma: Prevalence in 50 cases confirmed by molecular diagnostic studies. Am J Surg Pathol 24: 410-416, 2000.

59. Llombart B, Kindem S and Chust M: Merkel Cell carcinoma: An update of key imaging techniques, prognostic factors, treatment, and follow-up. Actas Dermosifiliogr 108: 98-107, 2017.

60. Karamchandani JR, Nielsen TO, van de Rijn M and West RB Sox10 and S100 in the diagnosis of soft-tissue neoplasms. Appl Immunohistochem Mol Morphol 20: 445-450, 2012.

61. Bartolomucci A, Possenti R, Mahata SK, Fischer-Colbrie R, Loh YP and Salton SR: The extended granin family: Structure, function, and biomedical implications. Endocr Rev 32: 755-797, 2011. 
62. Cheung CC, Kandel RA, Bell RS, Mathews RE and Ghazarian DM: Extraskeletal Ewing sarcoma in a 77-year-old woman. Arch Pathol Lab Med 125: 1358-1360, 2001.

63. Geens L, Robays JV, Geert V and der Speeten KV: An unusual location of extraosseous Ewing's sarcoma. Case Rep Oncol 6: 293-302, 2013

64. Shek TW, Chan GC, Khong PL, Chung LP and Cheung AN: Ewing sarcoma of the small intestine. J Pediatr Hematol Oncol 23: 530-532, 2001.

65. Maeda M, Tsuda A, Yamanishi S, Uchikoba Y, Fukunaga Y, Okita $\mathrm{H}$ and Hata J: Ewing sarcoma/primitive neuroectodermal tumor of the kidney in a child. Pediatr Blood Cancer 50: 180-183, 2008.

66. Park JY, Lee S, Kang HJ, Kim HS and Park SY: Primary Ewing's sarcoma-primitive neuroectodermal tumor of the uterus: A case report and literature review. Gynecol Oncol 106: 427-432, 2007.

67. Chao TK, Chang YL and Sheen TS: Extraskeletal Ewing's sarcoma of the scalp. J Laryngol Otol 114: 73-75, 2000.

68. Serlo JA, Helenius IJ, Sampo M, Vettenranta K, Saarinen-Pihkala UM, Kivivuori SM, Riikonen P, Kivioja A, Böhling T, Kallajoki M, et al: Ewing's sarcoma family of tumors in Finland during 1990-2009: A population-based study. Acta Oncol 52: 767-775, 2013.

69. Iwamoto Y: Diagnosis and treatment of Ewing's sarcoma. Jpn J Clin Oncol 37: 79-89, 2007.
70. Mori Y, Kinoshita S, Kanamori T, Kataoka H, Joh T, Iida S, Takemoto M, Kondo M, Kuroda J and Komatsu H: The successful treatment of metastatic extraosseous Ewing sarcoma with pazopanib. Intern Med 57: 2753-2757, 2018.

71. Engel RH and Evens AM: Oxidative stress and apoptosis: A new treatment paradigm in cancer. Front Biosci 11: 300-312, 2006.

72. Smith DG, Magwere T and Burchill SA: Oxidative stress and therapeutic opportunities: Focus on the Ewing's sarcoma family of tumors. Expert Rev Anticancer Ther 11: 229-249, 2011.

73. Fang J, Deng D, Nakamura H, Akuta T, Qin H, Iyer AK, Greish K and Maeda $\mathrm{H}$ : Oxystress inducing antitumor therapeutics via tumor-targeted delivery of PEG-conjugated D-amino acid oxidase. Int J Cancer 122: 1135-1144, 2008. 